\title{
Study on the impact of the Beijing-Shanghai high-speed railway on regional economic equity based on economic performance
}

\author{
Heng Yang ${ }^{1} \cdot$ Qiong Tong ${ }^{1} \cdot$ Pan Zhao $^{2}$
}

Received: 10 December 2020 / Accepted: 30 August 2021 / Published online: 26 September 2021

(c) The Author(s) 2021

\begin{abstract}
According to the panel data of stations along the Beijing-Shanghai high-speed railway (BSHR) from 2008 to 2018, the influence of BSHR on regional economy of cities along the line is analyzed, and the influence of the opening of the BSHR on regional economic equity of cities along the line, through constructing the difference-in-differences model. The research result shows that the opening of the BSHR greatly promotes the growth of the GDP per capita of the site cities along the line and the optimal allocation of resources, such as labor, information and technology, and accelerates the two-way flow of factors of production between big cities and small and medium-sized cities at stations along the high-speed railway, makes highquality resources from small and medium-sized cities flow to big cities along the line, while some backward resources from big cities gradually tilt toward small- and medium-sized cities along the line. In short, the opening of BSHR promotes the economic growth of the cities along the line, shortens the economic gap between the cities, is conducive to realizing regional economic equity.
\end{abstract}

JEL Classification L9 $\cdot \mathrm{Z} 1 \cdot \mathrm{E} 0$

Heng Yang

17113109@bjtu.edu.cn

Qiong Tong

qtong@bjtu.edu.cn

Pan Zhao

feng6123@126.com

1 Department of Economics and Management, Beijing Jiaotong University, No. 3 Shangyuancun, Haidian District, Beijing 100044, China

2 Beijing Aolunda Agricultural Technology Development Co., Ltd, Room 3019, Floor 3, Building 32, Yangguang Nanli Haidian District, Beijing 100044, China 


\section{Introduction}

After the opening of the first Shinkansen with the speed of more than $200 \mathrm{~km} / \mathrm{h}$ in Japan since 1964, the world started to enter into a high-speed railway (HR) era. After that, In subsequent decades, France, Germany, Spain, South Korea, and other developed countries have completed the HR construction. As the actual HR, Beijing-Tianjin Intercity Railway in China was opened in 2008. Although the construction of the HR in China is far later than foreign countries, the development of HR in China is rapid. The operation mileage of the HR has reached $35000 \mathrm{~km}$ in China by the end of the 2019 , occupying $70 \%$ of the total world operations, which arrives in the area covering all the provinces and cities except Tibet autonomous region. The rapid development of HR can not only produce far-reaching influence for the economy and society in China, but also become an important business card for foreign countries. Among them, the BSHR has played a certain role in promoting the fast development of HR construction in China, as the first HR with the longest line and the highest standard built by China.

With economic and social development, the construction of transportation infrastructure is closely related to economic development, and the construction of the HR also has a certain correlation. The HR has many advantages of high-speed, high comfort, high safety, and so on, which can not only improve the travel satisfaction of passengers, but also greatly compress the travel time of passengers, so the improvement of HR technology exists a certain externality. The paper has researched the influence of HR on regional economic equity, which is analyzed from the economic growth among cities along the BSHR. After the opening of the BSHR, the GDP per capita of these cities along the line continues to increase, and the GDP per capita gap decreases, which realized the regional economic equity. The GDP per capita data of station cities and surrounding non-station cities along the BSHR is selected as sample based on outcome fairness, so as to research the influence of the opening of the BSHR on the economic gap of cities along the BSHR, and obtain the influence of the BSHR on regional economic equity through the analysis on the influence of the BSHR on regional economic equity of cities along the line.

The research structure of this paper mainly includes the following: The first part is preface; The second part is literature review; The third part is the regional overview, data sources, and research assumptions; The fourth part is the regional analysis of the BSHR; The fifth part is the influence of the BSHR on regional economic equity along the line; The sixth part is relevant conclusions and suggestions.

\section{Literature review}

\subsection{Fairness and economic equity}

Fairness generally refers to access to fair distribution procedures (Thibaut and Walker 1975), distribution results (Adams 1966) and interaction methods (Bies 
and Moag 1986), otherwise, it can be called unfair. Fairness can be generally divided into opportunity fairness, procedural fairness, outcome fairness (Arneson 1989; Breen 2010) and efficiency and fairness (Zhu 2006). Opportunity fairness means that citizens get equal opportunities to participate, develop and share in economic activities according to law (Rawls 1988). Procedural justice refers to the fair rules and process that citizens obtain when they participate in economic activities according to law (Philpotts 1983). Outcome fairness means that citizens get and have equal distribution results (Philpotts 1983). Fairness and Efficiency means that fairness should adapt to the development of society, need to be combined with efficiency, is the unity of fairness and efficiency (Zhu 2006). Procedural justice refers to the fair rules and process that citizens obtain when they participate in economic activities according to law. Outcome fairness means that citizens get and have equal distribution results. And, fairness and efficiency mean that fairness should adapt to the development of society, need to be combined with efficiency, is the unity of fairness and efficiency. In social production and life, absolute fairness does not exist, it only exists in the pursuit of ideas, and the reality of fairness is a kind of relative fairness, and this relative fairness has a temporary nature, and with the change of the historical process fairness will change (Xu 2004).

Economic equity is a kind of distributive result equality under government intervention. When the social distribution is unfair, workers will be less enthusiastic and productive (Robinson and Eatwell 2009; He 2019). The construction of HR is a national project led by the government in China, which directly affects the accessibility and attractiveness of the region, and promotes transportation equity among regional cities (Yang and Tong 2020). At the same time, existing studies mostly study the impact of HR on the economy from the perspective of GDP or GDP per capita. Studies have found that the development of HR accelerates the mobility of production factors, improves the effective allocation of resources, and promotes the development of regional urban economy ( $\mathrm{Li}$ and Huang 2018; Wang and Li 2018; Ahlfeldt and Feddersen 2018). If HR reduces the economic gap between cities, it can be regarded as achieving outcome fairness under government intervention, and economic equity has been achieved. However, the promotion effect of HR on regional cities along the line is not consistent. For example, the influence of siphon effect on large cities and small and medium-sized cities increases the economic gap between cities along the line. The result does not realize distributive result equality, and it is called economic inequity.

\subsection{Vertical and horizontal transportation equity}

Transportation equity is regarded to be equal to the average distribution for space, so as to meet people's basic mobility needs (Hay and Trinder 1991), which mainly takes traffic items as research objects to evaluate the influence of traffic distribution at different time periods. Transportation equity is divided into horizontal equity and vertical equity at the earliest stage (Thomopoulos and Grant-Muller 2013) The horizontal equity strengthens the balanced distribution of interests among members of 
the same population, and the vertical equity pays more attention to the distribution of interests among members of the different populations (Lee and Douglass 1978). Then, Litman (2005) divides transportation equity into three aspects: Horizontal transportation equity refers that the difference of travel capacity and requirements between individuals or groups is not considered; The vertical transportation equity based on income difference and social class takes the differences among groups with income differences or different social classes into account; The vertical transportation equity based on travel capacity and requirements mainly takes population requirements with travel barriers into account.

What kind of fairness does traffic justice belong to? Most scholars believe that the core goal of transportation equity is usually achieved through accessibility (Guagliardo 2004), and transportation equity is opportunity fairness rather than outcome fairness, and to provide equal opportunities for social members to participate should be taken into consideration in social activities ( $\mathrm{Liu} 2007$; Li et al. 2018). However, some scholars have raised doubts, arguing that it is unreasonable to classify transportation equity only as opportunity fairness or outcome fairness, and transportation equity should be outcome fairness based on opportunity equity (Zou and Ye 2014; Lin et al. 2019). The existing research on transportation equity is widely used in urban transportation. The research methods mainly focus on Wilson entropy distribution (Shi et al. 2008; Shi and Zhang 2016), accessibility measure (Chen et al. 2015; Kelobonye et al. 2019; Neutens et al. 2010), Lorentz curve and Gini coefficient (Wu and Cao 2011) and, so on, and the research objects mainly focus on urban transportation cost (Chen et al. 2015), urban traffic policy (Dietz and Atkinson 2005; Pooya et al. 2017), and so on.

\subsection{Influence of HR on regional economic equity}

The existing researches on transportation infrastructure and regional economic development mainly focus on two aspects. Firstly, the construction of transportation infrastructure is conducive to the promotion of regional economic development (Kim 2000; Liu et al. 2009), for example, Japan (Komei et al. 1997), Germany (Yang 2017) and China (Fu 2018); secondly, the construction of transportation infrastructure does not have an obvious promotion on regional economic development (Evans and Karras 1994; Douglas and Lovely 2017). As a kind of advanced means of conveyance, the existing research on the construction of the HR and regional economy has not been a consistent conclusion, which is mainly concentrated in two aspects. Firstly, HR plays a significant role in promoting regional economy, and the construction of HR can optimize resource allocation, promote employment and industrial agglomeration, and form new growth point for regional economies (Vickerman 1997; Mo et al. 2018; Chen et al. 2018; Mcdonald and Osuji 1995; Lu and Zhan 2017; Wang and Li 2014); secondly, the HR does not have obvious influence on regional economies, and the HR mainly depends on the interior of HR construction project (Givoni 2006; Vickerman 1997).

The researched regional economic equity in the paper is a kind of result equity proposed by Adams in the 1960s, and the outcome fairness refers to the equal 
distribution of production results, which mainly strengthens the relative relationship between income shares. The existing research on HR and regional economic equity is concentrated in three aspects. Firstly, the HR construction improves the accessibility between regions (Ortega and López 2012; Mei et al. 2018; Li et al. 2017), realizes the reallocation of resources, and increases the economic gap between regions with and without HR (Chen and Hall 2012; Blum et al. 1997; Fang and Sun 2016); Secondly, after the opening of the HR, the gap of economic growth among areas with and without HR has been reduced, and the construction of the HR is conducive to promoting the regional economy (Ma et al. 2018); Thirdly, there is no correlation between the opening of HR and economic development, which cannot produce an influence on regional economic gap (Nakagawa and Hatoko 2007; Gabriel and Feddersen 2011; Wang and Nian 2014).

There are four main research methods to study the relationship between HR and economy. Firstly, through the "with or without comparison method" to analyze the changes of GDP, fixed asset investment, value-added of tertiary industry and other economic indicators of cities along the line before and after the opening of HR (Wang and Li 2014), but this method has some deviation and deficiency in practice. Secondly, through multiple linear regression model, scholars analyze the development of local economy with or without HR (Luo and Lin 2013; Zhang and $\mathrm{Wu} 2017$ ), but the factor chosen and the expression used for this factor are just guesses in the regression analysis by this method. This prediction affects the diversity and unpredictability of this factor, and the results of regression analysis are easily limited. Thirdly, using Solow Growth Model to construct CD production function to analyze the impact of HR on regional economy ( $\mathrm{Li}$ and Huang 2018). However, this model assumes that the steady state growth rate is exogenous, and cannot explain the rate of labor growth and technological progress. Many scholars believe that the externalization of growth rate is the main theoretical defect of Solow's model. Fourthly, the difference-in-differences (DID) is used to analyze the economic impact of HR (Ahlfeldt and Feddersen 2018; You and Zhen 2018; Wu et al. 2020). Because DID method can effectively avoid endogeneity problems, it can estimate policy effects more accurately by setting a dummy variable for regression analysis, and is often applied by scholars.

According to the above literature review and existing research results, there are many types of researches on the regional economy of HR at home and abroad, but there are few researches based on the perspective of transportation equity. Most of the existing researches focus on the comparison between the areas with and without a HR, but the comparative researches on the interior of the areas with HR are few. At the same time, some scholars deem that the development of HR has changed accessibility between regions, drives the flow of production factors to more attractive cities, reduces the development speed of other smalland medium-sized cities along the route, and creates "siphon effect" (Wang 2014; Huang and Wu 2020). Some scholars deem that the development of HR has changed accessibility between regions, drives the two-way flow of production factors to more attractive cities, and guides economic activities to be distributed along HR area. The industrial spatial distribution shows diffusing effect. 
The HR construction in China is different from foreign countries, which is all over the country to form reticular structure now and the covered areas have great differences. The research of this paper is from the perspective of outcome fairness and the basis of the achievements of travel opportunity fairness in the early stage to analyze the influence of the BSHR on regional economic development differences along the line, research the influence of the BSHR on regional economic equity, and broaden the research methods and fields of the influence of HR on regional economic equity, which have important reference value for the development of the HR, the realization of regional equity along the HR and the scientific layout of regional economic coordinated development.

\section{Regional overview, data sources, overview of early achievements and research hypothesis}

\subsection{Regional overview}

The BSHR was opened on June 30 in 2011 from Beijing in the north to Shanghai in the South. Its length is $1318 \mathrm{~km}$. The initial operation speed is $300 \mathrm{~km} / \mathrm{h}$. In September 2017, the operation speed of the BSHR is increased to $350 \mathrm{~km} / \mathrm{h}$ for the six cities of Shanghai, Jinan, Tianjin, Nanjing, Suzhou, and Beijing. The BSHR crosses the three municipalities of Shanghai, Tianjin and Beijing, and four provinces of Jiangsu, Anhui, Shandong and Hebei. The 23 station cities along the line include Shanghai, Kunshan, Suzhou, Wuxi, Changzhou, Danyang, Zhenjiang, Nanjing, Chuzhou, Dingyuan, Bengbu, Suzhou, Xuzhou, Zaozhuang, Tengzhou, Qufu, Tai' an, Jinan, Dezhou, Cangzhou, Tianjin, Langfang, and Beijing.

\subsection{Data sources}

The economic equity data in the research include urban GDP per capita, urban financial expenditure, investment in urban fixed assets, the value of urban tertiary industry and secondary industry, mileage of opened road, and the data are from the "Statistical Yearbook" and "Statistical Bulletin of National Economic and Social Development" of each province and city during 2008 to 2018. In the station cities along the BSHR, Beijing, Shanghai, Jinan, and Suzhou are big cities with larger economic volume, and it is difficult to find the economic volume adapt to them, so the prefecture-level cities along the BSHR are selected as research objects including the 12 cities of Langfang, Cangzhou, Dezhou, Jining, Tai' an, Zaozhuang, Suzhou, Chuzhou, Bengbu, Zhenjiang, Wuxi, and Changzhou, and the 14 cities of Chengde, Liaocheng, Laiwu, Heze, Linyi, Fuyang, Xuancheng, Yangzhou, Nantong, Lianyungang, Huai'an, Yancheng, Taizhou, and Suqian are selected as the comparison group. Data analysis is completed in Stata12.0. 


\subsection{Overview of early achievements}

In the previous research, regional accessibility model was used to analyze the change of accessibility of BSHR to cities along the route, and obtained the motivations of resource flow and the impact of the opening of BSHR on fairness of travel opportunities of cities at stations along the line. Regional accessibility model is mainly based on the comprehensive measure of the weighted travel time, and from time or cost savings point of view the weighted travel time measures accessibility of the city within the region, and related the spatial location of the central city and the quality of transportation facilities between cities. The weighted average travel time score of regional economic core cities is lower than that of peripheral areas. Finally, the dynamic changes of regional accessibility before and after the opening of BSHR and the speed increase after the opening of BSHR are obtained. The results show that after the operation and acceleration of BSHR, the weighted average travel time of the stations along the BSHR decreased from $413.96 \mathrm{~min}$ before the operation to $137.08 \mathrm{~min}$, and the standard deviation of weighted travel time decreases from 73.7 to 18.04. The opening and acceleration of BSHR has reduced the average travel time of the stations along the line, and greatly shortened the gap of the average travel time between the stations along the line, and promoted the realization of the fairness of travel opportunities in the stations along the line (Yang and Tong 2020).

\subsection{Research hypothesis}

The regional division in China is mainly the administration, and the regions are mainly composed of two or more administrative regions. Compared to the normal railway, the biggest feature of HR is fast. The opening and speed-up of the BSHR reduce the average travel time of stations along the BSHR, shorten the average travel time distance between stations along the BSHR, and promote the realization of the fairness of regional travel opportunities in cities along the BSHR. Because the transportation of the BSHR is mainly human, the "one-day round trip" makes it possible to separate the workplace and residence, which promotes the optimal allocation of labor, information, technology, and other resources and increases the polarization of regional economy. This polarization exists not only between cities with and without the high-speed, but also between cities with HR (Yang and Tong 2020). Therefore, the paper puts forward the following two hypotheses:

H1: There is a regional economy along the BSHR consisted of $1+\mathrm{N}$ regions. 1 refers to the station cities along the HR, and $\mathrm{N}$ refers to cities along the HR without opening.

H2: The opening of the HR will accelerate the development of economic of cities along the BSHR, which will close the increase of the economic gap between cities along with the railway stations due to the optimal allocation of resources. 


\section{Regional analysis along the BSHR}

With the rapid development of the HR in China, which has formed the four horizontal and four vertical HR networks. It is possible to have multiple HR lines in one area, and there are also many HR lines along the BSHR such as Beijing-Hong Kong HR and Jinan-Qingdao HR. This research takes December 31 in 2018 as the deadline to conduct statistics and division for the HR opening situation in cities along the BSHR according to the administrative area of the three municipalities and four provinces (Table 1).

According to the regional distribution in Table 1, the research divides the cities into the provincial capital cities with opened HR, the non-provincial capital cities with opened HR, county-level cities with opened HR and county-level cities without opened HR drawn in Fig. 1. As shown in Fig. 1, although there are many HR lines along the line, there is still more than one city without the opening of HR around the stations along the line. Taking Anhui as an example, the BSHR and Beijing-Hong Kong HR exist in Anhui at the same time, but there are still cities of Chaohu, Huai' an, and Yangzhou without the opening of HR around the Chuzhou. Therefore, there are regional economies composed of the station cities and the surrounding cities without the opening of HR along the BSHR, and the number of station city is equal or less than the surrounding cities without the opening of HR, which effectively verifies the $\mathrm{H} 1$ hypothesis.

\section{The empirical analysis of regional economic equity}

The research analyzes the influence of the opening of the BSHR on the station economy along the line to achieve the influence of the BSHR on economic equity of stations along the line through the comparison of changes in GDP per capita between the cities with and without HR before and after the opening of the BSHR by Difference-in-Differences.

\subsection{Selection basis of DID model}

This study selected DID model considering mainly from two aspects. Firstly, the opening of the HR can be seen as a policy, which is exogenous to a certain extent relative to the microeconomic subject, and DID model as a policy evaluation method can effectively avoid endogenous interference problem, and using fixed effects can ease the problem of omitted variable bias. Secondly, the traditional policy evaluation methods mostly carry out regression by setting dummy variables of whether the policy occurs or not, which cannot accurately estimate the policy effect, while DID model setting is more reasonable and effective.

Compared with traditional DID, spatial DID considers spatial correlation effect. This paper selects traditional DID instead of spatial DID mainly from two aspects. Firstly, BSHR is the first HR line in the real sense in China. From the perspective of 


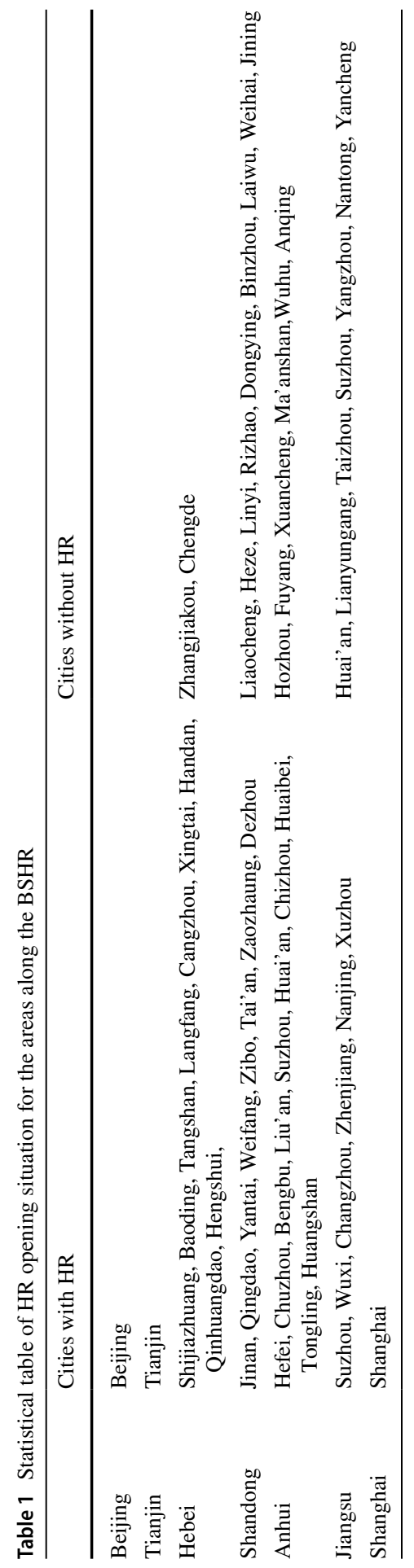




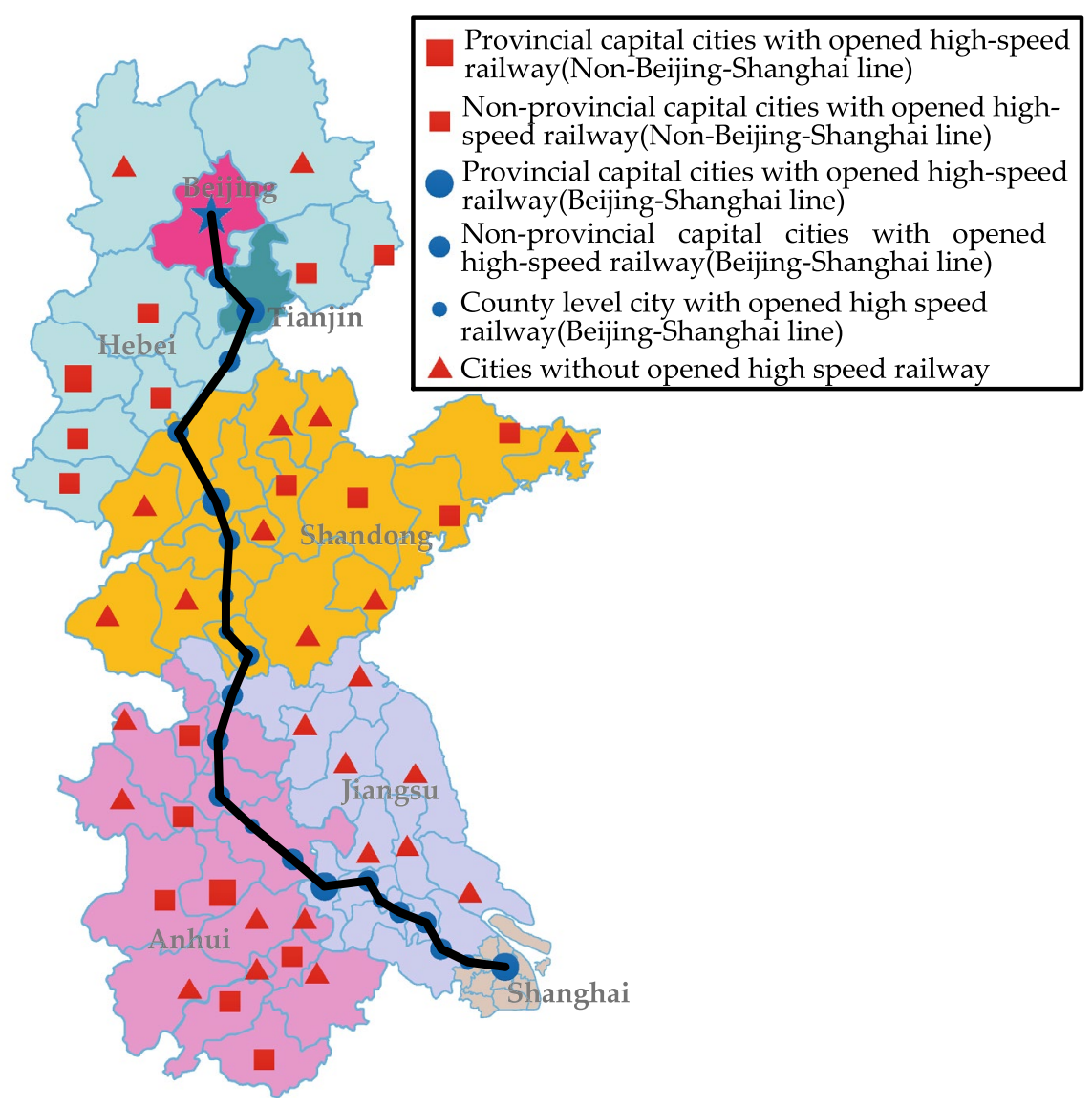

Fig. 1 Regional distribution along the line of BSHR

$\mathrm{HR}$, there is no indirect influence of other HR lines on cities along the BSHR. Secondly, regional economic development is mainly divided into administrative regions in China, and there are great differences among administrative regions. Meanwhile, within the same administrative region, each city is more affected by the provincial capital. In addition, the resource endowment of each city is different, so the influence between the two is less. In this paper, after excluding large cities such as Beijing, Shanghai and Jinan, 12 cities in the experimental group are distributed in 5 different provinces and municipalities directly under the central government, and none of which is the provincial capital city. Since each city is more influenced by the provincial capital city, the two cities have less influence on each other. In addition, this paper uses Stata software to conduct correlation analysis on the panel data of GDP per capita of 12 cities, and the maximum correlation coefficient (r) between two cities does not exceed 0.19 , indicating that the correlation between cities is extremely low. 


\subsection{The construction of Difference-in-Differences model}

Difference-in-Differences model takes the opening time of the BSHR as a deadline in 2010 (including this year). The time before 2010 is set before the opening of the BSHR, and the time after 2010 is set after the opening of the BSHR. The 12 station cities of Langfang, Cangzhou, Dezhou, Tai' an, Jining, Zaozhuang, Suzhou, Bengbu, Chuzhou, Zhenjiang, Changzhou, and Wuxi along the line are selected as the treatment group, and 14 cities without the opening of the HR before the end of 2018 including Chengde, Liaocheng, Laiwu, Heze, Linyi, Fuyang, Xuancheng, Yangzhou, Nantong, Lianyungang, Huai' an, Yancheng, Taizhou, and Suqian are selected as comparison group. The treatment group is the cities affected by the opening of the BSHR, and the comparison group is the cities with little or no influence by the opening of the BSHR. The construction of the model is shown as follows (Mo et al. 2018):

$$
Y_{i t}=\alpha_{0}+\alpha_{1} x_{i t}+\alpha_{2} d_{i t}+\alpha_{3} x_{i t} d_{i t}+\alpha_{4} z_{i t}+\varepsilon_{i t}
$$

$i$ and $t$ refer to the $t$-th year of the $s$-th city; The variables $Y_{i t}$ represents the economic effects of HR. This article mainly measures from GDP per capita; $x_{i t}$ is a dummy variable of time; $z_{i t}$ represents variables including fixed asset investment, fiscal expenditure, industrial structure, and Highway traffic mileage; $d_{i t}$ indicates grouped dummy variables; $x_{i t} d_{i t}$ is the cross-item of $x_{i t}$ and $d_{i t} . \alpha_{o}$ is the intercept of regression. $\varepsilon_{i t}$ is the random disturbance term. Add influencing factors to build the model and get:

$$
\begin{aligned}
Y_{i t}= & \alpha_{o}+\alpha_{1} x_{i t}+\alpha_{2} d_{i t}+\alpha_{3} d_{i t} x_{i t}+\alpha_{4} \text { Inhighway }_{i t}+\alpha_{5} \text { Inasset }_{i t} \\
& +\alpha_{6} \text { Infiscal }_{i t}+\alpha_{7} \text { industry }_{i t}+\varepsilon_{i t}
\end{aligned}
$$

$Y_{i t}$ is measured by the logarithm of GDP per capita; $x_{i t}$ reflects the status of opening $\mathrm{HR}$, the value is 1 in the year of opening HR and after, otherwise it is $0 ; d_{i t}$ as the treatment group is 1 , the comparison group is 0 ; lnasset $_{i t}$ indicates the logarithm of fixed asset investment; Infiscal ${ }_{i t}$ represents the logarithm of fiscal expenditure; industry $_{i t}$ is the industrial structure, and the ratio of the tertiary industry to the secondary industry in each city measured it; Inhighway ${ }_{i t}$ indicates a logarithm of highway mileage.

\subsection{Regression results and test analysis of the DID model}

\subsubsection{Descriptive statistical analysis of independent and dependent variables}

Based on the data of fixed asset investment, fiscal expenditure, industrial structure, highway traffic mileage and GDP per capita of cities along the BSHR from 2008 to 2018 , this paper conducts descriptive statistical analysis of cities with and without HR, and draws Tables 2 and 3. 


\begin{tabular}{|c|c|c|c|c|c|}
\hline$\stackrel{\infty}{\stackrel{\infty}{\sim}}$ & 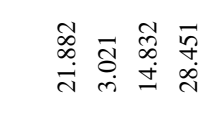 & 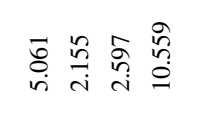 & 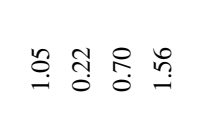 & 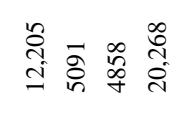 & 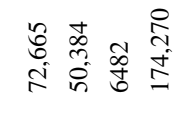 \\
\hline $\overrightarrow{\vec{i}}$ & 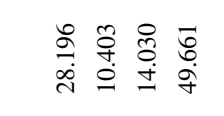 & 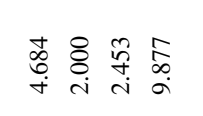 & 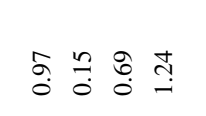 & 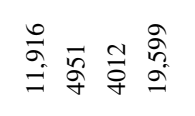 & 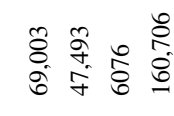 \\
\hline 芩 & 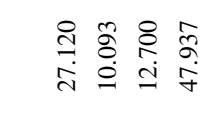 & 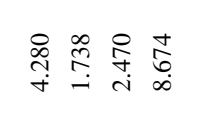 & 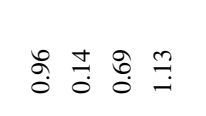 & 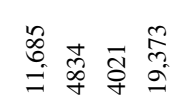 & 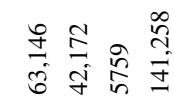 \\
\hline$\stackrel{n}{n}$ & 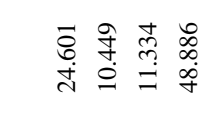 & 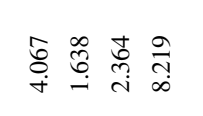 & 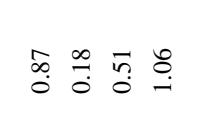 & 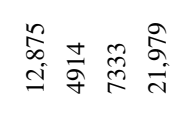 & 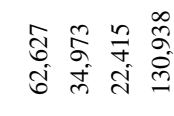 \\
\hline ते & 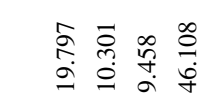 & 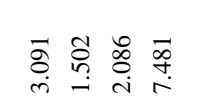 & 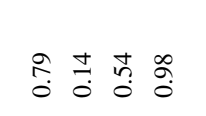 & 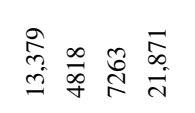 & 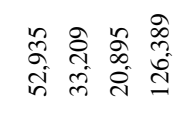 \\
\hline$\stackrel{n}{\text { }}$ & 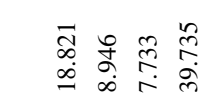 & 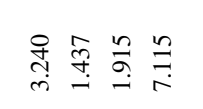 & 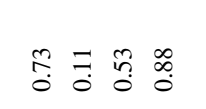 & 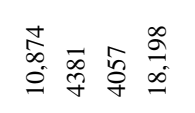 & 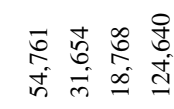 \\
\hline & 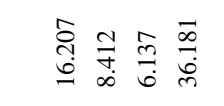 & 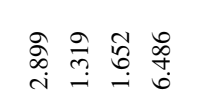 & 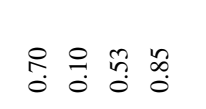 & 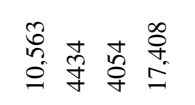 & 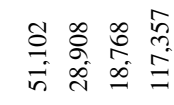 \\
\hline $\bar{z}$ & 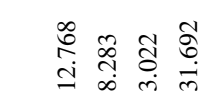 & 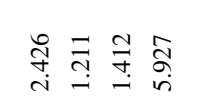 & 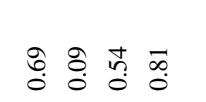 & 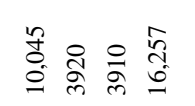 & 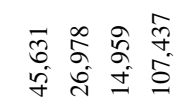 \\
\hline$\stackrel{\text { }}{\beth}$ & 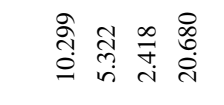 & 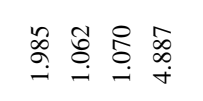 & 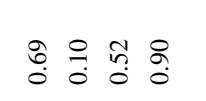 & 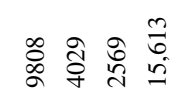 & 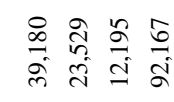 \\
\hline ฉ̊ & 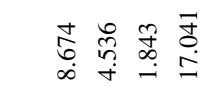 & 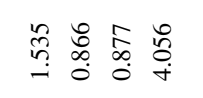 & 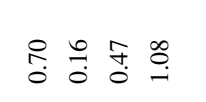 & 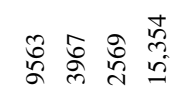 & 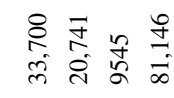 \\
\hline$\stackrel{\infty}{\stackrel{\alpha}{\circ}}$ & 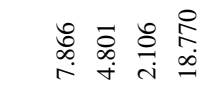 & 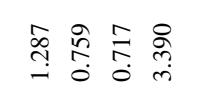 & 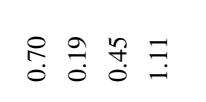 & 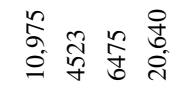 & 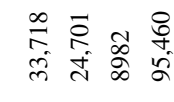 \\
\hline 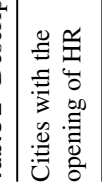 & \multicolumn{5}{|c|}{ 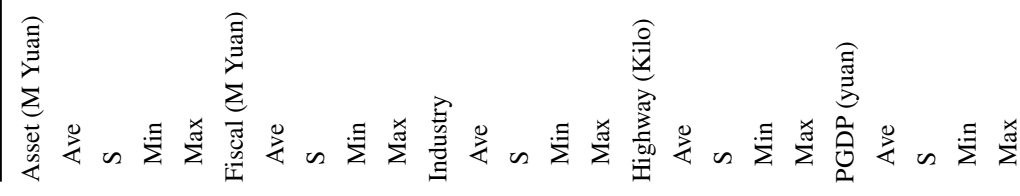 } \\
\hline
\end{tabular}


As can be seen from Table 2, from 2008 to 2018, the average of fixed asset investment of cities with HR increased from 7.866 to 21,882 , and the minimum increased from 2.106 to 14.832 , and the maximum increased from 18.77 to 28.451 . The fixed asset investment of cities with HR increased year by year along the line. From 2008 to 2018 , the average of fiscal expenditure of cities with HR increased from 1.287 to 5.061 , and the standard deviation increased from 0.759 to 2.155 , and the minimum increased from 0.717 to 2.597 , and the maximum increased from 3.390 to 10.559 . The fiscal expenditure of cities with HR is increasing year by year along the BSHR. From 2008 to 2018, the average of industrial structure of cities with HR increased from 0.7 to 1.05 , and the minimum increased from 0.45 to 0.7 . The industrial structure of cities with HR increased year by year along the BSHR. From 2008 to 2018, the average highway mileage of cities with HR increased from 10,975 to 12,205, and the maximum increased from 20,640 to 20,268 . There was little change in the highway mileage of cities with HR along BSHR. From 2008 to 2018, the average GDP per capita of cities with HR increased from 33,718 to 72,665, and the standard deviation increased from 24,701 to 50,384 , and the maximum value increased from 95,460 to 174,270 . The GDP per capita of cities with HR increased year by year along the BSHR.

As can be seen from Table 3, from 2008 to 2018, the average of fixed asset investment of cities without HR increased from 6.739 to 28.168 , and the minimum increased from 1.889 to 16.487 , and the maximum increased from 15.054 to 24.644. The fixed investment of cities without HR increased year by year along the BSHR. From 2008 to 2018, the average fiscal expenditure of cities without HR increased from 1.141 to 5.008 , and the standard deviation increased from 0.380 to 2.140 , and the maximum increased from 1.962 to 8.772 . The fiscal expenditure of cities without HR is increasing year by year along the BSHR. From 2008 to 2018, the average industrial structure of cities without HR increased from 0.65 to 0.98 , and the industrial structure of cities without HR year by year along the BSHR. From 2008 to 2018 , the average, standard deviation, maximum and minimum of highway mileage in cities without HR all showed amplitude state. From 2008 to 2018, the average GDP per capita of cities without HR increased from 20,693 to 66,090, and the standard deviation increased from 9,058 to 30,508 , and the minimum increased from 6,475 to 21,589 , and the maximum increased from 35,846 to 120,944 . The GDP per capita of cities without HR is increasing year by year along the BSHR.

\subsubsection{Analysis of regression results}

Construct panel data of the GDP per capita (PGDP) against fixed asset investment, fiscal expenditure, tertiary industry to secondary industry ratio and highway mileage of the comparison group and the treatment group from 2008 to 2018, set grouping dummy variables and time dummy variables. Through Stata12.0 software, we get three regression results of the mixed model (POLS), fixed effect model (FE), and random effect model (RE), and the three regression models were compared using the Hausman test and $\mathrm{F}$ test. The Hausman test is based on the $P$ value. When the $P$ value is greater than 0.05 , the random effect model is superior to the fixed effect model, and the random effect model is selected. Otherwise, the fixed effect model is 


\begin{tabular}{|c|c|c|c|c|c|}
\hline$\stackrel{\infty}{\stackrel{i}{\sim}}$ & ભે & 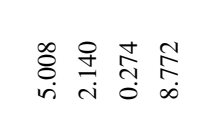 & 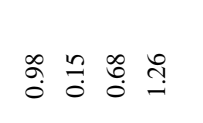 & 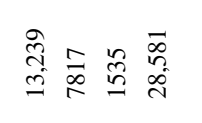 & 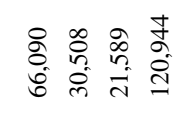 \\
\hline ते & 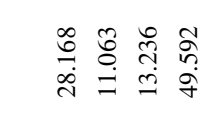 & 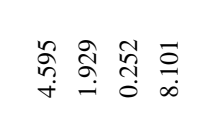 & $\stackrel{0}{0} \underset{0}{0} \stackrel{t}{0} \stackrel{0}{=}$ & 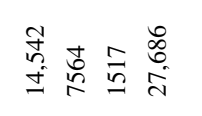 & 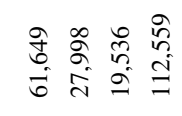 \\
\hline 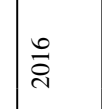 & 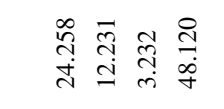 & 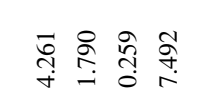 & 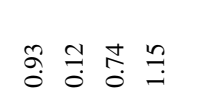 & 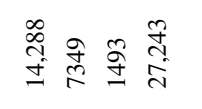 & 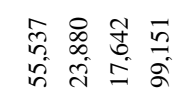 \\
\hline & 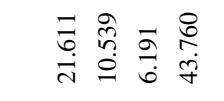 & 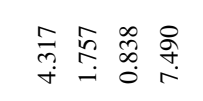 & 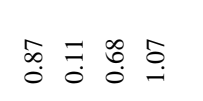 & 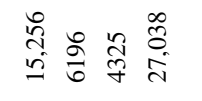 & 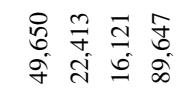 \\
\hline ते & 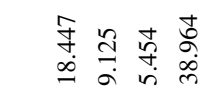 & 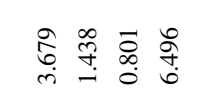 & $\begin{array}{ccc}\vec{\infty} & = \\
0 & 0 \\
0 & 0 & 0 \\
0 & 0\end{array}$ & 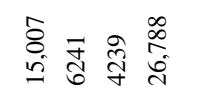 & 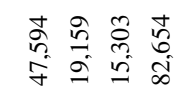 \\
\hline & 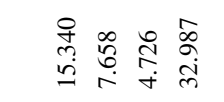 & 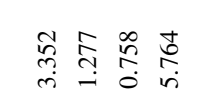 & $\stackrel{\circ}{=} \overrightarrow{0} \tilde{\sigma}$ & 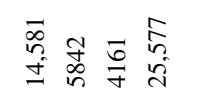 & 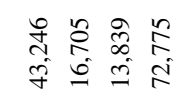 \\
\hline & 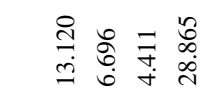 & 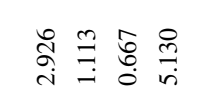 & 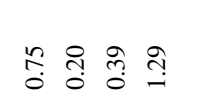 & 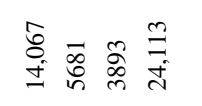 & 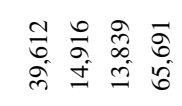 \\
\hline & 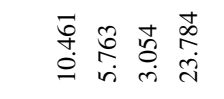 & 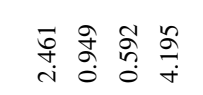 & 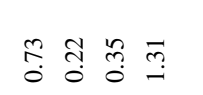 & 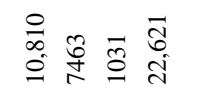 & 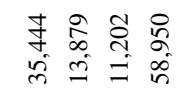 \\
\hline & 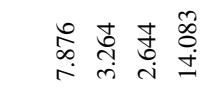 & 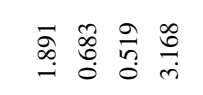 & 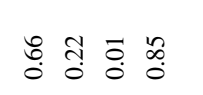 & 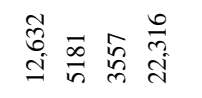 & 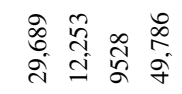 \\
\hline ¿े & 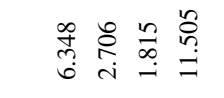 & 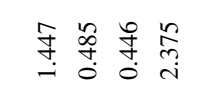 & فํ. & 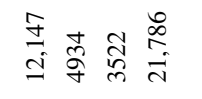 & 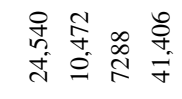 \\
\hline$\stackrel{\circ}{8}$ & 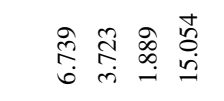 & 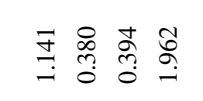 & 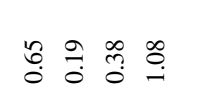 & 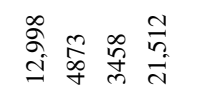 & 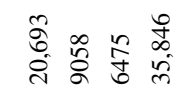 \\
\hline 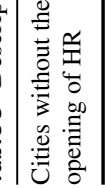 & \multicolumn{5}{|c|}{ 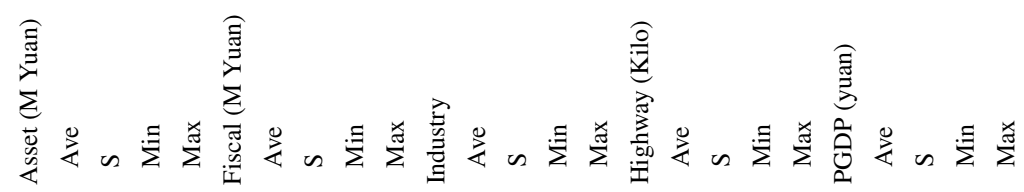 } \\
\hline
\end{tabular}


selected. The F test is based on the $\mathrm{P}$ value as well. When the $P$ value is greater than 0.05 , the mixed effect model is superior to the fixed effect model, and the mixed effect model is selected. Otherwise, the fixed effect model is selected. According to the mixed model (POLS), FE, and (RE) derived from this study, Table 4 is constructed.

According to the data in Table 4 in the Hausman test, the $\mathrm{P}$ value is 0.0000 , which is less than 0.05 , rejecting the original hypothesis, indicating that the fixed effect is better than the random utility, and the fixed utility is selected. In the F test, the P value is 0.0000 , less than 0.05 , rejecting the original hypothesis, indicating that the fixed utility is better than the mixed utility, and the fixed utility is selected. From the results of the Hausman test and F test, the regression results of the DID model select a fixed utility model, that is Table 5 .

According to Table 5, the coefficient of crossover coefficient (gp) is 0.0004802 , which shows a positive value, and the $P$ value is 0.067 , which is less than 0.1 , indicating that the opening of the HR has a positive correlation with the growth of GDP per capita of cities along the BSHR. The fixed asset investment and industrial structure coefficients of cities along the BSHR are -0.0015999 and -0.0013886 respectively, showing negative values, and the $P$ value is all 0.001 , which is less than 0.01 , indicating that the BSHR has a negative impact on the GDP per capita of cities along the BSHR. The coefficients of fiscal expenditures and highway mileage of stations along the route are 0.0033551 and 0.1149168 , which are shown as positive values, and the $P$ value is 0.000 , which is less than 0.01 , indicating that the BSHR has a positive impact on the GDP per capita of cities along the route.

In summary, the opening of the BSHR can effectively promote the growth of GDP per capita of cities along the BSHR. Among them, the growth of fixed asset investment in cities along the route and changes in industrial structure has a depressing effect on the growth of urban GDP per capita. The increase in city fiscal expenditure and the increase in highway mileage have a promoting effect on the growth of urban GDP per capita. The opening of the HR has promoted the flow of production factors such as information, technology, talent, and capital, and promoted the development of industries such as commerce, logistics, and services, thereby driving the economic development of cities along the route. Therefore, the opening of HR has a positive impact on the economic growth of cities with stations along the HSBR.

\subsubsection{Parallel trend hypothesis test}

The parallel trend test is the foundation on which the regression results of the DID model can be established. It mainly analyzes the time trend of the GDP per capita of cities along with the BSHR site and the GDP per capita of the surrounding HR cities before and after the opening of the HR to test the impact of the policy on the treatment group. The parallel hypothesis test is set to two periods (Pre) before the HR is opened and (Post) after the HR is opened. Among them, before the opening of the HR, 2008 was used as the base year to analyze the time trend of the comparison group and the treatment group; After the HR was opened, 2011 as the starting time was used to analyze the time trend of the comparison group and the treatment group. The qualification conditions of the parallel trend test need to have two conditions at 
the same time: First, before the opening of the BSHR, the effect of the HR displayed by the fixed effect model is irrelevant, and the comparison group and the treatment group show the same time trend; Second, after opening the Beijing-Shanghai highspeed, the fixed effect model showed that the effect of HR was correlated, and the comparison group and the treatment group showed different time trends. According to the panel data-parallel trend test results, Table 6 can be obtained.

According to Table 6, Pre2 and Pre3 represent 2009 and 2010 before the opening of the BSHR, and Post1, Post2, Post3, Post4, Post5, Post6, Post7, and Post8 respectively represent 2011, 2012, 2013, 2014, 2015, 2016, 2017 and 2018 after the opening of the BSHR Years. According to (Pre)PGDPFE, the regression P values of Pre2 and Pre 3 are both greater than 0.1 , indicating that the impact of HR in these two periods is not related. According to (Post)PGDPFE, after the BSHR is opened, the regression coefficients of Post1, Post2, and Post 3 are P values of 0.00104, 0.000824, and 0.000699 , respectively, showing positive values, and the $\mathrm{P}$ values are less than $0.01,0.05$, and 0.1 , respectively. The impact effect showed a positive correlation, and the correlation gradually weakened. The P values of Post4, Post5, Post6, Post7, and Post8 were all greater than 0.1 , indicating that the impact of HR gradually disappeared.

Draw Fig. 2 according to the parallel trend test. It can be seen from Fig. 2 that before the BSHR was opened, the time trends of GDP per capita of the comparison group and the treatment group were consistent. After the BSHR was opened, the GDP per capita of the treatment group was continuously and positively affected by the opening of the HR. And the effect gradually weakened, and its influence gradually disappeared in the fourth year after the HR opened, meeting the parallel trend test.

\subsubsection{Comparative analysis of cities within the line along the BSHR}

Statistical analysis was carried out on the panel data of GDP per capita from 23 stations along the Beijing-Shanghai line from 2008 to 2018 (Table 7), and Fig. 3 was drawn. According to Table 7 and Fig. 3, the average GDP per capita of cities along the BSHR has increased from 43,140.91 yuan in 2008 to $100,949.96$ yuan in 2018, and the standard deviation has increased from 26,981.24 yuan in 2008 to $55,397.41$ yuan in 2018. The minimum value increased from 6406.00 yuan in 2008 to $24,893.00$ yuan in 2018 , and the maximum value increased from $120,882.00$ yuan in 2008 to $230,270.00$ yuan in 2018 . Among them, in the first year of opening the BSHR, the standard deviation increased from 2169.23 to 4356.30. Since average and standard deviation values are different, and there's a big difference between their numbers in each year, we will use coefficient of variation to analyze the degree of dispersion. The coefficient of variation decreased from 0.625 in 2008 to 0.549 in 2018, and the lowest point reached 0.528. Although there was a slight fluctuation in some years, the overall trend was downward and the variability was gradually decreasing. After the opening of the BSHR, as the GDP per capita of cities along the BSHR increased year by year, the gap in GDP per capita among cities also decreased year by year. 
Table 4 POLS, FE, and RE regression analysis

\begin{tabular}{|c|c|c|c|}
\hline & $\begin{array}{l}\text { (1) } \\
\text { PGDPPOLS }\end{array}$ & $\begin{array}{l}(2) \\
\text { PGDPFE }\end{array}$ & $\begin{array}{l}(3) \\
\text { PGDPRE }\end{array}$ \\
\hline$d_{i t}$ & $\begin{array}{l}0.000397 \\
(1.24)\end{array}$ & $\begin{array}{l}0 \\
(.)\end{array}$ & $\begin{array}{l}0.000655 \\
(1.56)\end{array}$ \\
\hline$x_{i t}$ & $\begin{array}{l}-0.00106^{* * * *} \\
(-3.54)\end{array}$ & $\begin{array}{l}-0.00119 * * * \\
(-4.35)\end{array}$ & $\begin{array}{l}-0.00104 * * * \\
(-3.90)\end{array}$ \\
\hline gp & $\begin{array}{l}0.000683 * \\
(1.83)\end{array}$ & $\begin{array}{l}0.000480 * \\
(1.84)\end{array}$ & $\begin{array}{l}0.000526^{*} \\
(1.92)\end{array}$ \\
\hline lnasset & $\begin{array}{l}-0.00135 * * * \\
(-2.83)\end{array}$ & $\begin{array}{l}-0.00160 * * * \\
(-3.49)\end{array}$ & $\begin{array}{l}-0.00150 * * * \\
(-3.30)\end{array}$ \\
\hline lnfiscal & $\begin{array}{l}0.00234 * * * \\
(4.04)\end{array}$ & $\begin{array}{l}0.00336 * * * \\
(5.11)\end{array}$ & $\begin{array}{l}0.00275 * * * \\
(4.46)\end{array}$ \\
\hline Industry & $\begin{array}{l}-0.000395 \\
(-0.78)\end{array}$ & $\begin{array}{l}-0.00139 * * * \\
(-3.26)\end{array}$ & $\begin{array}{l}-0.00115^{* * * *} \\
(-2.66)\end{array}$ \\
\hline lnhighway & $\begin{array}{l}0.112 * * * \\
(286.76)\end{array}$ & $\begin{array}{l}0.115^{* * *} \\
(293.07)\end{array}$ & $\begin{array}{l}0.114 * * * \\
(295.20)\end{array}$ \\
\hline _cons & $\begin{array}{l}0.153 * * * \\
(94.38)\end{array}$ & $\begin{array}{l}0.140 * * * \\
(75.74)\end{array}$ & $\begin{array}{l}0.143^{* * * *} \\
(81.41)\end{array}$ \\
\hline F Test & $\begin{array}{l}F=15,483.67 \\
P=0.0000\end{array}$ & & \\
\hline Hausman Test & & $\begin{array}{l}P=0.0000 \\
\text { Chi } 2=-41.24\end{array}$ & \\
\hline Sample capacity & 286 & 286 & 286 \\
\hline
\end{tabular}

$* P<0.1 ; * * P<0.05 ; * * * P<0.01$

\subsubsection{Comparative analysis of cities with and without HR along the BSHR}

By comparing the change of standard deviation of per capita GDP of cities with and without HR along the BSHR from 2010 to 2018 (Table 8), Fig. 4 is drawn. The variation coefficient of GDP per capita in cities without HR decreased from 0.204 in 2008 to 0.085 in 2018, showed a downward trend and then an upward trend. In particular, the rebound point in 2018 is higher than in 2008. This shows that the

Table 5 FE DID regression analysis

\begin{tabular}{lllll}
\hline PGDP & Coef & Std. Err & $\mathrm{t}$ & $P>\mathrm{t}$ \\
\hline$d_{i t}$ & 0 & (omitted) & & \\
$x_{i t}$ & -0.001194 & 0.0002746 & -4.35 & 0.000 \\
gp & 0.0004802 & 0.0002613 & 1.84 & 0.067 \\
lnasset & -0.0015999 & 0.0004582 & -3.49 & 0.001 \\
lnfiscal & 0.0033551 & 0.0006565 & 5.11 & 0.000 \\
industry & -0.0013886 & 0.0004259 & -3.26 & 0.001 \\
lnhighway & 0.1149168 & 0.0003921 & 293.07 & 0.000 \\
cons & 0.1399844 & 0.0018482 & 75.74 & 0.000 \\
\hline$* P<0.1 ; * * P<0.05 ; * * * P<0.01$ & & &
\end{tabular}


development trend of the whole economic environment shows great volatility and explains the reason why the variation coefficient of cities with HSR increased in 2017 and 2018. The variation coefficient of per capita GDP of cities with or without HR along the BSHR decreased first and then increased from 2008 to 2018. However, the deceleration of variation coefficient of per capita GDP in cities with HR was significantly higher than cities without HR, and the D-value decreased from 0.204 in 2008 to 0.085 in 2018. Through comparative analysis, regardless of whether the BSHR is built or not, the economic gap between all cities along the line first decreases and then expands. However, after the opening of the BSHR, the spillover effect generated by the BSHR accelerates the narrowing of the economic growth gap. Even when the overall economic growth gap widened between 2017 and 2018, the effect of HR on inhibiting growth was still obvious.

In summary, the opening of the BSHR has a positive correlation with the GDP per capita of the site cities along the route, and promotes the growth of the GDP per capita of the site cities along the line. All cities along the BSHR are developing differently, and the growth gap between cities is narrowing. The opening of BSHR has changed the accessibility and attractiveness of cities with HR, stimulated the flow of production factors, and made resources from cities without HR flow to cities with HR, produced siphon effect. At the same time, according to the analysis of the cities with BSHR, the opening of BSHR has greatly promoted the bi-directional optimal allocation of resources, makes high-quality resources from small and medium-sized cities along the line flow to big cities, while some backward resources from big cities gradually tilt to small and medium-sized cities. This resource allocation generates siphon effect and diffusion effect. In a word, the opening of BSHR has promoted the economic growth of the cities along the line, shortened the economic gap between the cities, realized regional economic fairness, and effectively verifies the validity of $\mathrm{H} 2$ hypothesis.

\section{Conclusions and recommendations}

The economic changes of station areas along the BSHR before and after the opening of the BSHR are analyzed combing with the Difference-in-Differences model through the calculation of accessibility and economic influence of stations along the BSHR in the paper. The average GDP per capita of cities along the BSHR is increased from 43,140.91 yuan in 2008 to $100,949.96$ yuan in 2018. The coefficient of variation decreased from 0.625 in 2008 to 0.549 in 2018. The opening of the BSHR promotes the growth of GDP per capita for station cities along the line and optimizes the allocation of resources between cities. The siphonic effect and spillover effect have realized the two-way allocation of resources. Under the two effects, the per capita GDP gap between the cities has been decreasing along the BSHR, which is conducive to the realization of regional economic equity and outcome fairness. Based on the existing conclusions, this paper puts forward three aspects of thinking: 
Table 6 Parallel trend test

\begin{tabular}{|c|c|c|}
\hline & $\begin{array}{l}\text { (Pre) } \\
\text { PGDPFE }\end{array}$ & $\begin{array}{l}\text { (Post) } \\
\text { PGDPFE }\end{array}$ \\
\hline$d_{i t}$ & $\begin{array}{l}0 \\
(.)\end{array}$ & $\begin{array}{l}-0.00151 * * * \\
(-4.84)\end{array}$ \\
\hline$x_{i t}$ & $\begin{array}{l}-0.00125 * * * \\
(-4.46)\end{array}$ & $\begin{array}{l}0 \\
\text { (.) }\end{array}$ \\
\hline lnasset & $\begin{array}{l}-0.00160 * * * \\
(-3.49)\end{array}$ & $\begin{array}{l}-0.00139 * * * \\
(-2.90)\end{array}$ \\
\hline lnfiscal & $\begin{array}{l}0.00354 * * * \\
(5.19)\end{array}$ & $\begin{array}{l}0.00381 * * * \\
(5.46)\end{array}$ \\
\hline industry & $\begin{array}{l}-0.00144 * * * \\
(-3.35)\end{array}$ & $\begin{array}{l}-0.00109 * * \\
(-2.36)\end{array}$ \\
\hline lnhighway & $\begin{array}{l}0.115^{* * *} * \\
(290.16)\end{array}$ & $\begin{array}{l}0.115^{* * * *} \\
(290.91)\end{array}$ \\
\hline Pre 2 & $\begin{array}{l}-0.0000941 \\
(-1.01)\end{array}$ & \\
\hline Pre 3 & $\begin{array}{l}-0.000422 \\
(1.43)\end{array}$ & \\
\hline Post 1 & & $\begin{array}{l}0.00104 * * * \\
(2.60)\end{array}$ \\
\hline Post 2 & & $\begin{array}{l}0.000824 * * \\
(2.15)\end{array}$ \\
\hline Post 3 & & $\begin{array}{l}0.000699 * \\
(1.85)\end{array}$ \\
\hline Post 4 & & $\begin{array}{l}0.000287 \\
(0.77)\end{array}$ \\
\hline Post 5 & & $\begin{array}{l}0.000163 \\
(0.44)\end{array}$ \\
\hline Post 6 & & $\begin{array}{l}0.000475 \\
(1.27)\end{array}$ \\
\hline Post 7 & & $\begin{array}{l}0.000313 \\
(0.83)\end{array}$ \\
\hline Post 8 & & $\begin{array}{l}0.000112 \\
(0.29)\end{array}$ \\
\hline _cons & $\begin{array}{l}0.140 * * * \\
(75.31)\end{array}$ & $\begin{array}{l}-14,853.3 * * * \\
(-6.57)\end{array}$ \\
\hline Sample capacity & 286 & 286 \\
\hline
\end{tabular}

$* P<0.1 ; * * P<0.05 ; * * * P<0.01$

1. The siphonic effect and spillover effect of HR validates the necessity of changing Chinese society's principal contradiction. Through the trend of economic growth among all cities along the BSHR, we can find that the overall economic growth gap between cities in China shows a floating trend, and the buoyancy is large. The opening of HR has a promotion effect when the overall economic growth gap presents a downward trend, and has a restraining effect when the overall economic growth gap presents an upward trend. This economic development model can no longer match the needs of people to pursue a better life. Therefore, president $\mathrm{Xi}$ 


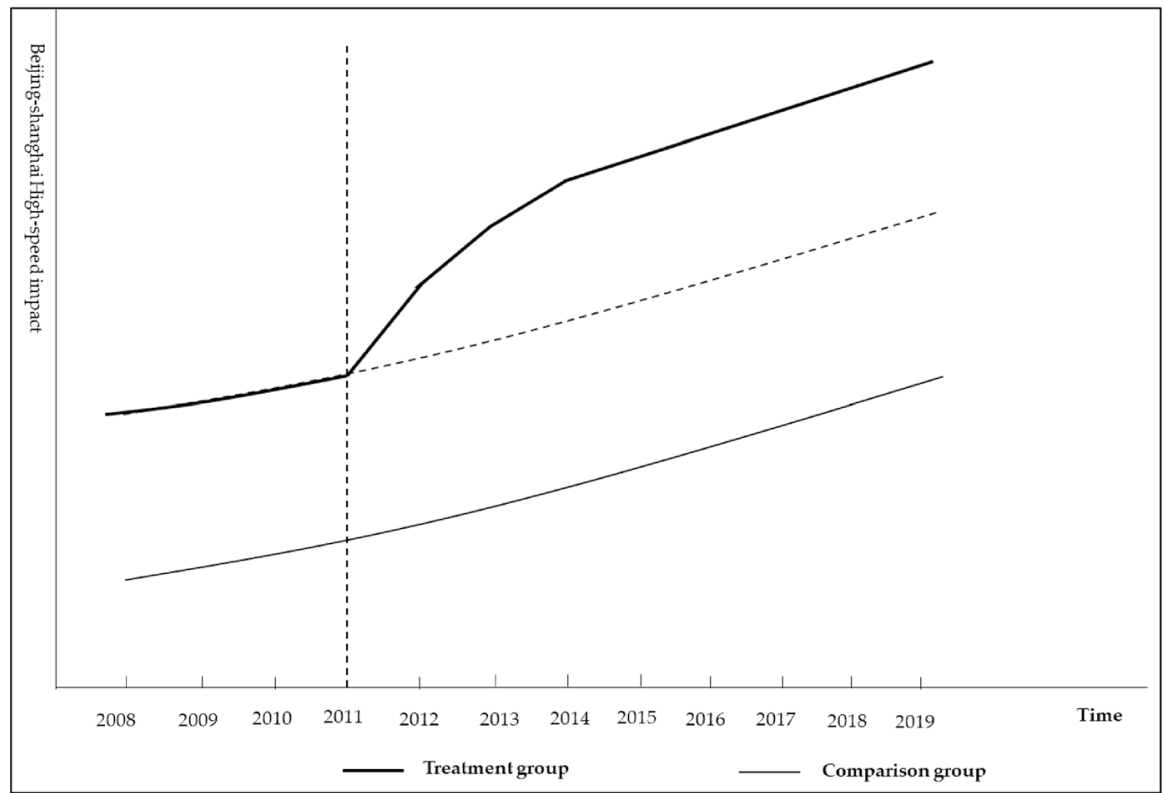

Fig. 2 Impact of the opening of the BSHR on the per capita GDP of cities along the BSHR

Jinping reported to principal contradiction facing Chinese society in a new era, which has become The contradiction between people's growing need for a better life and unbalanced and inadequate development in the 19th National Congress On October 18, 2017. The construction of HR promotes the economic growth of cities along the line, is conducive to narrowing the economic gap between cities along the line and solving the existing major contradictions, and meets the requirements of the new era in China.

Table 7 Statistical description of GDP per capita of 23 sites

\begin{tabular}{lllrrr}
\hline PGDP (Yuan) & Average & Standard deviation & Minimum & Maximum & $\begin{array}{c}\text { Coefficient } \\
\text { of variation }\end{array}$ \\
\hline 2008 & $43,140.91$ & $26,981.24$ & 6406.00 & $120,882.00$ & 0.625 \\
2009 & $46,768.22$ & $29,362.67$ & 7480.00 & $135,361.00$ & 0.628 \\
2010 & $53,340.83$ & $31,531.90$ & 8939.00 & $142,185.00$ & 0.591 \\
2011 & $60,603.04$ & $33,750.54$ & $10,578.00$ & $147,186.00$ & 0.557 \\
2012 & $67,193.22$ & $37,609.28$ & $11,936.00$ & $165,291.00$ & 0.560 \\
2013 & $73,153.52$ & $40,609.81$ & $13,370.00$ & $177,923.00$ & 0.555 \\
2014 & $78,362.87$ & $42,314.04$ & $14,645.00$ & $182,222.00$ & 0.540 \\
2015 & $82,763.35$ & $44,233.88$ & $15,950.00$ & $186,580.00$ & 0.534 \\
2016 & $88,404.04$ & $46,640.71$ & $17,176.00$ & $191,056.00$ & 0.528 \\
2017 & $95,854.61$ & $51,041.11$ & $18,804.00$ & $212,103.00$ & 0.530 \\
2018 & $100,949.96$ & $55,397.41$ & $20,681.00$ & $230,270.00$ & 0.549 \\
\hline
\end{tabular}




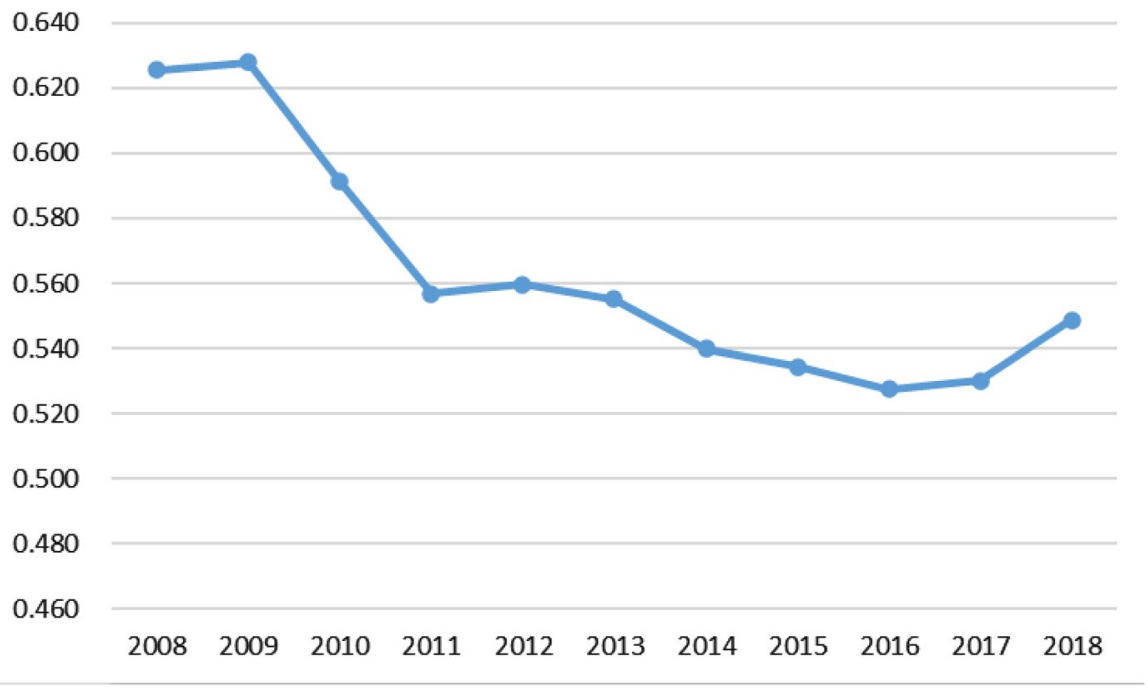

Fig. 3 Changes in the GDP per capita gap of 23 cities (Yuan)

2. The effect of HR has produced from siphon effect to diffusion effect. From the research results of this paper, it can be found that if the opening of BSHR only produces siphon effect, the development of small and medium-sized cities will be inhibited, but the result is not the case, which indicates that the BSHR also produces diffusion effect after the siphon effect. Under the influence of two effects, cities along the HR should seize the opportunities to complete the positioning of urban agglomerations, and realize the professional division for the stations along the line. Station cities along HR should conduct differential development. For example, big cities transfer low-end industries and upgrade high-end industries, and small and medium-sized cities undertake industrial transfer and conduct differential competition, which can realize the optimal allocation of resources through the professional division of industry among station cities along the HR. At the same time, the opening of HR has effectively improved the level of economic connection of cities along the line and promoted the development of urban agglomeration ( $\mathrm{Li}$ et al. 2018).

3. The effect of HR effectively validates that transportation equity is outcome fairness based on opportunity fairness. Based on the perspective of opportunity fairness and distributive fairness, the previous research results analyzed that the opening of BSHR significantly reduced the gap of average travel time between stations along the BSHR and promoted the realization of fairness of travel opportunities among stations along the BSHR. Based on the previous results and from the perspective of outcome fairness, this study concluded that the opening of BSHR promoted the growth of per capita GDP of the cities along the BSHR, and promoted the increasing gap of per capita GDP among the cities along the BSHR, which was not conducive to the realization of regional economic equity. Both studies show that transportation equity is not only about opportunity equity, 
Table 8 Comparative analysis of cities with and without HR along the BSHR

\begin{tabular}{llll}
\hline $\begin{array}{l}\text { Coefficient of } \\
\text { variation }\end{array}$ & $\begin{array}{l}\text { Cities with the } \\
\text { opening of HR }\end{array}$ & $\begin{array}{l}\text { Cities without the } \\
\text { opening of HR }\end{array}$ & $D$-value \\
\hline 2008 & 0.625 & 0.422 & 0.204 \\
2009 & 0.628 & 0.411 & 0.217 \\
2010 & 0.591 & 0.398 & 0.193 \\
2011 & 0.557 & 0.377 & 0.180 \\
2012 & 0.560 & 0.377 & 0.183 \\
2013 & 0.555 & 0.376 & 0.179 \\
2014 & 0.540 & 0.392 & 0.148 \\
2015 & 0.534 & 0.407 & 0.127 \\
2016 & 0.528 & 0.419 & 0.109 \\
2017 & 0.530 & 0.438 & 0.093 \\
2018 & 0.549 & 0.449 & 0.085 \\
\hline
\end{tabular}

3

\subsection{0}

0.200

0.150

0.100

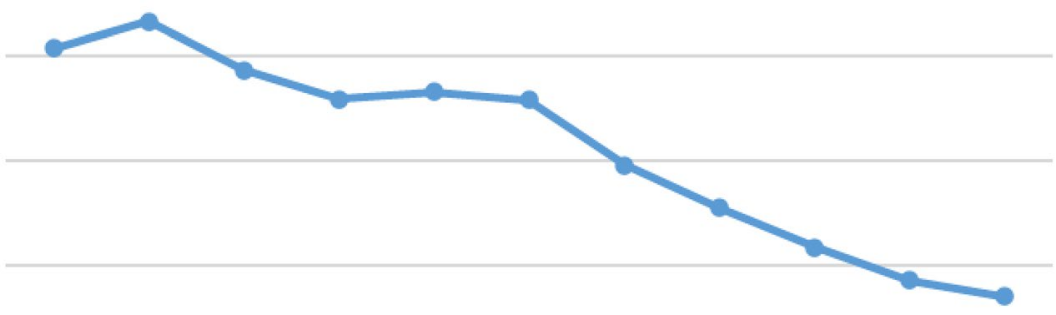

0.050

0.000

$\begin{array}{lllllllllll}2008 & 2009 & 2010 & 2011 & 2012 & 2013 & 2014 & 2015 & 2016 & 2017 & 2018\end{array}$

Fig. 4 Comparison of the gap between cities with and without HR along the BSHR

distributive fairness or result equity, but also result equity based on opportunity equity and distributive fairness.

Acknowledgements We thank the editors and reviewers for their critical comments to improve our paper. Furthermore, we also thank the support by China Social Science Foundation Major Project "Research on High-speed Rail Theoretical Framework and Evolutionary Path” under grant number 17ZDA084.

Authors contributions Heng Yang conceived and wrote the paper; The tutor, Qiong Tong, guided and reviewed the paper; Heng Yang and Pan Zhao collected and analyzed the data. All authors contributed to the paper and approved the submitted version. 
Funding This research was funded by China Social Science Foundation Major Project "Research on High-speed Rail Theoretical Framework and Evolutionary Path", Grant Number 17ZDA084.

Availability of data and materials The data are from the "Statistical Yearbook" and "Statistical Bulletin of National Economic and Social Development" of each province and city during 2008 to 2018 in China.

\section{Declarations}

Conflict of interest and Consent to publish There is no conflict of interest exits in the submission of this manuscript, and manuscript is approved by all authors for publication. I would like to declare on behalf of my co-authors that the work described was original research that has not been published previously, and not under consideration for publication elsewhere, in whole or in part. All the authors listed have approved the manuscript that is enclosed.

Ethical approval This study was carried out in accordance with the recommendations of ethical guidelines of the Ethical Review Board of Beijing Jiaotong University BJ202010017. The protocol was approved by the Ethical Review Board of Beijing Jiaotong University. All subjects gave written informed consent in accordance with the Declaration of Helsinki. The studies involving human participants were reviewed and approved by Beijing Jiaotong University.

Consent to participate All participants freely give consent to submit the paper and understand the rule of copyright.

Open Access This article is licensed under a Creative Commons Attribution 4.0 International License, which permits use, sharing, adaptation, distribution and reproduction in any medium or format, as long as you give appropriate credit to the original author(s) and the source, provide a link to the Creative Commons licence, and indicate if changes were made. The images or other third party material in this article are included in the article's Creative Commons licence, unless indicated otherwise in a credit line to the material. If material is not included in the article's Creative Commons licence and your intended use is not permitted by statutory regulation or exceeds the permitted use, you will need to obtain permission directly from the copyright holder. To view a copy of this licence, visit http://creativecommons.org/licen ses/by/4.0/.

\section{References}

Adams JS (1966) Inequity in social exchange. Inf Syst Res 2(4):267-299

Ahlfeldt GM, Feddersen A (2018) From periphery to core: measuring agglomeration effects using highspeed rail. J Econ Geography 2:355-390

Arneson RJ (1989) Equality and equal opportunity for welfare. Philos Stud 56(1):77-93

Bies RJ, Moag JF (1986) Interactional justice: communication criteria of fairness. Res Negotiat Organ 1(3):43-55

Blum U, Haynes KE, Karlsson C (1997) Introduction to the special issue the regional and urban effects of high-speed trains. Ann Region Sci 31(1):1-20

Breen R (2010) Social mobility and equality of opportunity geary lecture spring 2010. Econ Soc Rev 41(4):413-428

Chen CL, Hall P (2012) The wider spatial-economic impacts of high-speed trains: a comparative case study of Manchester and Lille sub-regions. J Transp Geogr 24:89-110

Chen F, Zhe XF, Ji X, Zhang HD (2015) The measurement method and spatial differentiation of urban transport equity. Econ Geography 35:70-75+113

Chen LW, Wang R, Liu JL (2018) Study on influence of high-speed railway on urban house priceempirical analysis based on shijiazhuang-wuhan high speed railway panel data. Resource Dev Market 34(10):1413-1417 
Dietz S, Atkinson G (2005) Public perceptions of equity in environmental policy: traffic emissions policy in an English urban area. Local Environ 10(4):445-459

Douglas H, Lovely ME (2017) Scale economies, returns to variety, and the productivity of public infrastructure. Int Econ Integr Domestic Perform 10:73-91

Evans P, Karras G (1994) Is government capital productive? Evidence from a panel of seven countries. J Macroecon 16(2):271-279

Fang DC, Sun MY (2016) An evaluation on the impact of high-speed rail on economic development of city clusters in the Yangtze River Delta - an empirical study based on difference in differences model, East China. Econ Manag 40(2):42-47

Fu XY (2018) Research on the impact of high-speed railway construction on economic development of the regions along the Line-taking Beijing-Shanghai High-speed Railway as an example. J Hubei Corresp Univ 31(9):115-116

Gabriel A, Feddersen A (2011) From periphery to core: economic adjustments to high speed rail. In: 51st Congress of the European Regional Science Association: New Challenges for European Regions and Urban Areas in a Globalised World, Barcelona, Spain

Givoni M (2006) Development and impact of the modern high-speed train: a review. Transp Rev 26(5):593-611

Guagliardo MF (2004) Spatial accessibility of primary care: concepts, methods and challenges. Int J Health Geogr 3(1):3

Hay A, Trinder E (1991) Concepts of equity, fairness, and justice expressed by local transport policymakers. Environ Plann C-Govern Policy 9(4):453-465

He J (2019) The riddle of economic equity and efficiency. Mod Mark 02:106-107

Huang ZN, Wu LC (2020) The impact of Beijing-Shanghai high-speed railway on urban economy: an empirical analysis based on spatial economics theory. Macroeconomic 2:165-175

Kelobonye K, Mccarney G, Xia J, Swapan MSH, Mao F, Zhou H (2019) Relative accessibility analysis for key land uses: a spatial equity perspective. J Transp Geogr 75:82-93

Kim KS (2000) High-speed rail developments and spatial restructuring. Cities 17(4):251-262

Komei S, Ohashi T, Ando A (1997) High-speed rail transit impact on regional systems: does the Shinkansen contribute to dispersion? Ann Reg Sci 31(1):77-98

Lee J, Douglass B (1978) Making the concept of equity operational. Transp Res Rec 677:48-53

Li XG, Huang AM (2018) Spillovers effect of the high-speed railway on counties' economic growth: taking Fujian Province as an example. Scientia Geographica Sinica 02:233-241

Li T, Ma W, Gao XC, Cao XS (2017) Evaluating the impacts of the Xiamen-Shenzhen high-speed railways on accessibility and its differentiation: a super-DEA approach. Econ Geogr 37(8):67-76

Li Y, Wang P, Liang JW (2018) Analysis on the change and impact of high-speed rail construction on the spatial economic correlation of the Guangdong-Hong Kong-Macao Greater Bay Area. J Guangdong Univ Finance Econ 158(03):35-45

Litman T (2005) Evaluating transportation equity. World Transp Policy Pract 2(8):50-65

Liu Y (2007) Transportation equity and traffic policy choices. J Shandong Agric Manag Cadre Inst 23(3):92-94

Liu XH, Zhang X, Peng MM (2009) Traffic infrastructure investment and regional economic growth-an empirical analysis on the case of western development. Areal Res Dev 04:57-61

Lin XY, Zhang ZH, Wang ZL (2019) Study on transportation equity measurement in china: based on traffic Gini coefficient analysis. Macroeconomic Study (5)

Lu FC, Zhan XZ (2017) Impact of high-speed railway on urban industrial agglomeration along the line: an empirical analysis based on the panel data from the cities in Central China. Contemp Finance Econ 38(11):88-99

Luo S, Lin XY (2013) An empirical study on the impact evaluation of high-speed railway on China's economy. Explor Econ Issues 11:74-78

Ma HM, Liu ZH, Yang DD (2018) Evaluation of the Impact of High-speed Railway on regional Economic Development-Empirical Analysis of Guizhou Province based on DID Model. J Guangxi Univ (philos Soc Sci) 40(5):88-92

Mcdonald JF, Osuji CI (1995) The effect of anticipated transportation improvement on residential land values. Reg Sci Urban Econ 25(3):261-278

Mei L, Huang BS, Ao RJ, Gao J (2018) The spatial pattern and evolution of high-speed railways accessibility of the urban agglomeration in the middle reaches of the Yangtze River. Econ Geogr 38(6):62-68 
Mo YL, Huang X, Liu X (2018) Study on the economic impact of high-speed railway on Guangdong and Guangxi - the empirical analysis based on DID econometric model. Reform Strategy 34(7):67-81

Nakagawa D, Hatoko M (2007) Reevaluation of Japanese high-speed rail construction: recent situation of the north corridor Shinkansen and its way to completion. Transp Policy 14(02):0-164

Neutens T, Versichele M, Schwanen T (2010) Arranging place and time: a GIS toolkit to assess personbased accessibility of urban opportunities. Appl Geogr 30(4):561-575

Ortega E, López E (2012) Territorial cohesion impacts of high-speed rail at different planning levels. J Transp Geogr 24(9):130-141

Philpotts G (1983) Applied fairness theory: comment. Am Econ Rev 73(5):1157-1160

Pooya N, Mohammad TI, Mohammad L, Jean-Claude T (2017) Evaluating traffic safety policies for developing countries based on equity considerations. J Transp Saf Secur 9(1):178-203

Rawls JB (1988) A theory of justice, vol 7. China Social Sciences Press, Beijing, pp 7-8

Robinson J, Eatwell J (2009) Introduction to modern economics. The Commercial Press

Shi L, Zhang T (2016) Local Spatio-temporal equality analysis of transit services. Bull Surv Mapp 62(5):45-49

Shi J, Yang L, Ying XW (2008) A quantitative evaluation model of transportation equity based on Wilson entropy distribution hypothesis. J Wuhan Univ Technol 32(1):1-4

Thibaut J, Walker L (1975) Procedural justice: a psychological analysis. Erlbaum, Hillsdale

Thomopoulos N, Grant-Muller S (2013) Incorporating equity as part of the wider impacts in transport infrastructure assessment: an application of the SUMINI approach. Transportation 40:315-345

Vickerman R (1997) High-speed rail in Europe: experience and issues for future development. Ann Reg Sci 31(1):21-38

Wang DG (2014) Influence of Beijing-Shanghai high-speed railway on the spatial and temporal distribution of tourist flow at main stations. Tourism Tribune 1:75-82

Wang JF, Li ZG (2014) An empirical analysis of the influence of Shanghai-Hangzhou High-speed Railway on regional economic development along the Line. Inquiry Econ Issues 35(9):74-77

Wang P, Li YM (2018) The impact of high-speed rail on the evolution of economic agglomeration in urban agglomerations: a case study of three urban agglomerations in China. Urban Problems 05:64-74

Wang Y, Nian M (2014) Did high-speed trains promote the development of Regional economy? Shanghai Econ Rev 02:84-93

Wu ML, Cao K (2011) Quantitative evaluation method of traffic fairness based on Gini coefficient. Technol Econ Areas Commun 13(01):86-89

Wu GH, Zhang XJ, Li YQ (2020) The influence of high-speed railway on the development of urban tourism economy based on the PSM-DID model. J Huaqiao Univ 5:53-64

Xu DJ (2004) Absolute fairness and relative fairness. Stud Ethics 000(006):66-69

Yang L (2017) The substantiality of the region and its policy implication. Theore Discuss 34(4):169-172

Yang H, Tong Q (2020) The impact of the Beijing-Shanghai high-speed railway on equity of regional cities. Manag Rev 32(02):90-101

You SB, Zhen LC (2018) Evaluation of economic pulling effect of high-speed railway on medium-sized cities along the line. Reform 10:150-159

Zhang L, Wu XT (2017) An empirical analysis of the effect of high-speed rail on urban economic growth. Stat Decis 17:152-154

Zhu CH (2006) Ethical analysis of governmental coordination of economic efficiency and economic fairness. J Zhengzhou Univ 39(3):27-29

Zou TD, Ye H (2014) The substitution effect of formal equity and operational efficiency: pension reform based on substantive equity. Econ Res J 3:115-129

Publisher's Note Springer Nature remains neutral with regard to jurisdictional claims in published maps and institutional affiliations. 